\title{
Dynamic mechanical properties and morphology characteristics of rubber- toughened poly(lactic acid)
}

\author{
Mohd Shaiful Zaidi Mat Desa ${ }^{1}$, Azman Hassan ${ }^{2,}$, Agus Arsad $^{3}$, and Masleeyati Yusop ${ }^{4}$ \\ ${ }^{1}$ Faculty of Chemical \& Natural Resources Engineering, Universiti Malaysia Pahang, Lebuhraya Tun \\ Razak, 26300 Gambang, Pahang, Malaysia. \\ ${ }^{2}$ School of Chemical and Energy Engineering, Faculty of Engineering, Universiti Teknologi Malaysia, \\ 81310 Johor Bahru, Johor, Malaysia. \\ ${ }^{3}$ School of Chemical and Energy Engineering, Faculty of Engineering, Universiti Teknologi Malaysia, \\ 81310 Johor Bahru, Johor, Malaysia. \\ ${ }^{4}$ Faculty of Science, Universiti Teknologi Malaysia, 81310 Johor Bahru, Johor, Malaysia.
}

\begin{abstract}
This study investigates the effect of natural rubber (NR), epoxidised natural rubber (ENR), and core-shell rubber (CSR) as toughening agents for poly(lactic acid) (PLA). PLA/rubber blends were prepared by using melt blending method in a twin-screw extruder, with the content of rubbers was fixed at 5 wt. \%. All PLA/rubber blends exhibited lower storage modulus compared to neat PLA. Two-stage storage modulus (E') was also observed, where the first stage occurred at lower temperature corresponded to the glass transition temperature $\left(\mathrm{T}_{\mathrm{g}}\right)$ of rubber components, whereas the second E' corresponded to the $\mathrm{T}_{\mathrm{g}}$ of PLA. The impact fracture surface of PLA/rubber blends also exhibited phaseseparated morphology where the spherical-shaped rubber particles were clearly present in the PLA matrix.
\end{abstract}

\section{Introduction}

Poly(lactic acid) (PLA) is an important biopolymer class that is typically derived from carbohydrate fermentation of agricultural products such as corn. PLA is widely regarded as a "green polymer" due to its biodegradable characteristics, where the polymer chain of PLA can be degraded into carbon dioxide $\left(\mathrm{CO}_{2}\right)$ and water $\left(\mathrm{H}_{2} \mathrm{O}\right)$ [1]. It also possesses high strength and stiffness that are suitable for many commercial applications. For this reason, PLA offers a very promising alternative to replace conventional petroleum-based plastics [2]. However, the brittleness of PLA is considered as a major problem, which hinders the use of PLA in commercial applications, especially in the area that requires mechanical toughness.

To make PLA fully competitive with conventional petroleum-based polymers, it is necessary to further improve its toughness. The use of rubber as an impact modifier for pure PLA has caught the attention of researchers due to its apparent toughening effect [3-9]. At present, the use of natural rubber (NR) as an impact modifier for PLA is becoming increasingly attractive due to low cost and renewability factor. Unlike other types of impact 
modifiers, NR has very low glass transition temperature $\left(\mathrm{T}_{\mathrm{g}}\right)$, is highly flexible, and can be easily manipulated through epoxidisation or grafting with a polar monomer to enhance its compatibility with PLA $[6,10,11]$. The new generation of rubber-toughening agent involves the preparation of structured core-shell rubber (CSR) particles. CSR is a preformed elastomeric particle comprises a rubbery core encapsulated in a thin layer of glassy shell [12].

The presence of rubber phase in PLA may be able to produce a new polymer material with improved toughness and simultaneously exhibits good mechanical strength and thermal properties. Previous studies also suggest that the optimum contents for toughness enhancement of polymers can be achieved at lower rubber contents (typically between 5 to $10 \mathrm{wt} \%)[5,6]$. Therefore, in this study, the toughening effect of NR, epoxidised natural rubber (ENR), and CSR on the dynamic mechanical properties of PLA was investigated. The contents of NR, ENR, and CSR were fixed at $5 \mathrm{wt} \%$ for all formulations, to ensure meaningful comparison of toughening effect. Morphology analysis was also conducted to examine the distribution and interaction of rubber particles in PLA matrix.

\section{Experimental}

\subsection{Materials}

Injection-grade PLA (PLA 1323A) was purchased from Shenzen Esun Industrial Co. Ltd. (China) with density of $1.35 \mathrm{~g} \mathrm{~cm}^{-3}$, melt index of $7 \mathrm{~g} / 10 \mathrm{~min}$, and melting temperature of $150{ }^{\circ} \mathrm{C}$. NR of Pureprena grade with specific gravity of 0.92 and $\mathrm{T}_{\mathrm{g}}$ of $-70^{\circ} \mathrm{C}$ was donated by the Malaysian Rubber Board. The main component is cis-1,4-polyisoprene with less than $0.01 \%$ concentration of hydroxylamine and less than $0.02 \%$ protease content. ENR with $50 \mathrm{~mol} \%$ epoxidisation of Ekoprena grade, $\mathrm{T}_{\mathrm{g}}$ of $-25{ }^{\circ} \mathrm{C}$, and specific gravity of 0.92 was also donated by the Malaysian Rubber Board. It contains cis-polyisoprene with $95 \%$ hydrocarbon. CSR (Paraloid ${ }^{\mathrm{TM}}$ EXL-3330) with melting point range of $132-149{ }^{\circ} \mathrm{C}$ and $\mathrm{T}_{\mathrm{g}}$ of $-43{ }^{\circ} \mathrm{C}$ was supplied by Rohm and Haas (USA). It consists of $97 \%-98 \%$ of cross-linked poly(butyl acrylate) (PBA) core grafted with poly(methyl methacrylate) (PMMA) shell, $2 \%-3 \%$ calcium carbonate, and less than $0.1 \%$ of individual residual monomer. It had white pellet form and was used as received.

\subsection{Blend preparation}

PLA and rubbers blend were prepared using melt-blending techniques, with contents of rubbers were kept at $5 \mathrm{wt} \%$. Before mixing and extrusion process, NR and ENR were masticated for 20 minutes, with temperature kept below $40{ }^{\circ} \mathrm{C}$. After that, all blend components (PLA, CSR, NR, and ENR) were weight accordingly and dried for $24 \mathrm{~h}$ at 40 ${ }^{\circ} \mathrm{C}$ in a vacuum oven to remove moisture. Melt blending of PLA and rubbers were then carried out in a counter-rotating twin screw extruder. Extruded samples were pelletized and injection moulded into test specimens for further testing.

\subsection{Dynamic mechanical analysis}

Dynamic mechanical properties were measured by a dynamic mechanical analyser (TA Instruments Thermal Analysis), which was to determine storage modulus (E'), loss modulus (E"), and $\tan \delta$ of the nanocomposites as a function of temperature (T). The dimensions of the samples for dynamic mechanical analysis (DMA) were $50 \times 12 \times 3 \mathrm{~mm}^{3}$. The test was conducted on a dual-cantilever fixture and the device was operated by setting 
$50 \mathrm{~N}$ as the static load and $\pm 25 \mathrm{~N}$ as the dynamic load with a heating rate of $25^{\circ} \mathrm{C} \mathrm{min}^{-1}$ in a broad temperature range $\left(-80\right.$ to $\left.120^{\circ} \mathrm{C}\right)$ at the frequency of $1 \mathrm{~Hz}$. However, the temperature range of neat PLA was done starting from room temperature (around $37^{\circ} \mathrm{C}$ ) to $120{ }^{\circ} \mathrm{C}$. The higher starting temperature of neat PLA as compared to other formulations is due to absence of rubber components, where sub-zero DMA analysis causes the PLA specimen to be extremely brittle and fails during analysis.

\subsection{Field emission scanning electron microscopy}

The phase morphologies of PLA and rubber blends were observed using Carls Zeiss Supra 35 field emission scanning electron microscopy (FESEM) with $10 \mathrm{~mm}$ working distance and accelerating voltage of $10 \mathrm{kV}$. All samples were coated with thin layer of gold prior to observation under the electron beam.

\section{Results and discussion}

Previously, a significant improvement of PLA toughness with the use of NR, ENR, and CSR as toughening agents was reported [13]. However, the Young's modulus and tensile strength exhibited a notable decrease, whereas differential scanning calorimetry (DSC) analysis also showed decreased $\mathrm{T}_{\mathrm{g}}$ compared to neat PLA. This article further discusses the effect of NR, ENR, and CSR as toughening agents on the dynamic mechanical properties and morphology characteristics of PLA/rubber blends.

\subsection{Dynamic mechanical analysis}

By comparing with neat PLA, the result from storage modulus analysis shows a significant decrease of E' for all rubber toughened PLA (Figure 1). This observation is expected due to the presence of low modulus rubber phase in the PLA matrix. However, it is notable that PLA/CSR and PLA/ENR show higher E' than PLA/NR. This observation is consistent with the static mechanical properties observed earlier and closely related with better interactions between ENR and CSR with the PLA matrix. All rubber-toughened PLA blends also display a decrease of E' at two different temperatures. Firstly, a gradual decrease for PLA/NR and PLA/CSR was observed between -65 and $-30{ }^{\circ} \mathrm{C}$, whereas a decrease of temperature between -20 and $10{ }^{\circ} \mathrm{C}$ was observed for PLA/ENR. It is noted that the first stage decrease of $E^{\prime}$ corresponds to the $T_{g}$ of the rubber phase in the system. Subsequently, a sharp decrease of E' was observed for all PLA/rubber blends between 65 and $75{ }^{\circ} \mathrm{C}$, which represents the $T_{g}$ region of PLA matrix. Above this temperature region, $E^{\prime}$ exhibits minimum intensity due to the changes of PLA mechanical character from rigid to flexible [14]. 


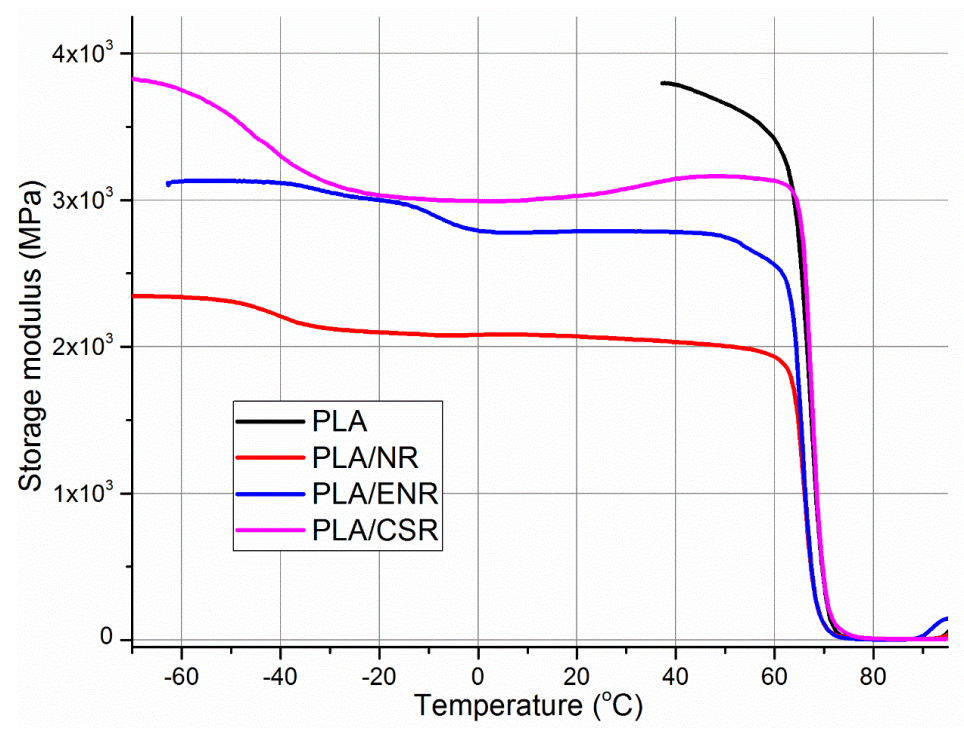

Fig. 1. The storage modulus of neat PLA, PLA/NR, PLA/ENR, and PLA/CSR.

The $\tan \delta$ curve shown in Fig. 2 clearly exhibits two $\mathrm{T}_{\mathrm{g}}$ transition regions for all PLA/rubber blends, which correspond to the $\mathrm{T}_{\mathrm{g}}$ of PLA and its respective rubber components. The $\mathrm{T}_{\mathrm{g}}$ of rubber components was clearly present at around $-60{ }^{\circ} \mathrm{C}(\mathrm{PLA} / \mathrm{NR})$, $-45.7^{\circ} \mathrm{C}$ (PLA/CSR), and $-8.8^{\circ} \mathrm{C}$ (PLA/ENR), whereas a huge tan $\delta$ peak of PLA matrix occurred around 70 to $75^{\circ} \mathrm{C}$. This indicates that the blends of PLA/rubber are immiscible. It is notable that PLA/NR blend exhibits the largest decrease of $70.8{ }^{\circ} \mathrm{C}$ as compared to $74.2{ }^{\circ} \mathrm{C}$ for neat PLA. Similarly, a decreasing trend of $T_{g}$ was also shown by PLA/CSR and PLA/ENR blends, where the values reduced by 2.6 and $2.2^{\circ} \mathrm{C}$, respectively. The decreasing trend is quite consistent with the decreasing $\mathrm{T}_{\mathrm{g}}$ trend observed earlier in DSC analysis; hence, this reaffirms the low modulus and high impact strength observed in mechanical analysis. Moreover, higher intensity of $\tan \delta$ peak displayed by PLA/rubber blends also indicates that more energy is dissipated in the blend, which is also related to high impact strength [15]. 


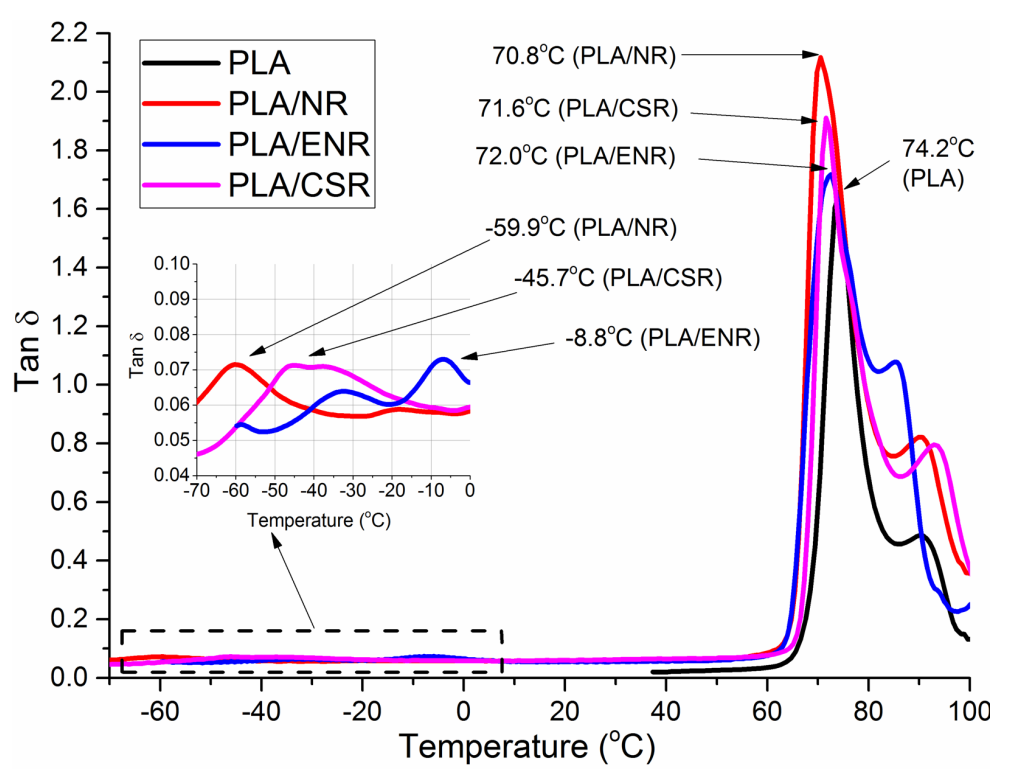

Fig. 2. Tan $\delta$ of neat PLA, PLA/NR, PLA/ENR, and PLA/CSR.

\subsection{Field emission scanning electron microscopy}

Figure 3 shows FESEM micrographs examined from the impact fracture surface of PLA/rubber blends. It can be seen that all rubber particles show phase separated morphology with PLA matrix. The presence of rubber particles in PLA matrix is exhibited either in the form of spherical particles or black holes, depending on the interfacial adhesion between rubbers and the surrounding matrix. The presence of many black holes in PLA/NR (marked by dotted yellow circles) is related with the low interfacial adhesion between PLA and NR (Figure 3(a)). This observation clearly reflects the incompatibility between PLA and NR due to the non-polarity of NR chains that hinder the interaction with polar PLA molecules.

In contrast, the impact fracture morphology of PLA/ENR (Figure 3(b)) shows plenty of rubber particles remained attached to the PLA matrix even after the impact action (marked by dotted yellow circles), indicating good interfacial adhesion between the two phases (i.e., PLA and ENR particles). The good interaction between ENR and PLA is expected due to the polar characteristic of both polymers. The morphology of PLA/CSR blend shows an even distribution of CSR particles among the PLA matrix (Figure 3(c)). CSR spherical particles (marked by dotted yellow circles) attached in the impact fracture surface are present in fairly large numbers, which indicates considerable interfacial adhesion between CSR and the surrounding PLA matrix. It is assumed that the high polarity of PMMA shell and the dipole force interaction between ester groups of PMMA and PLA might have contributed to the good interfacial adhesion between CSR and PLA (Figure 3(c)). 


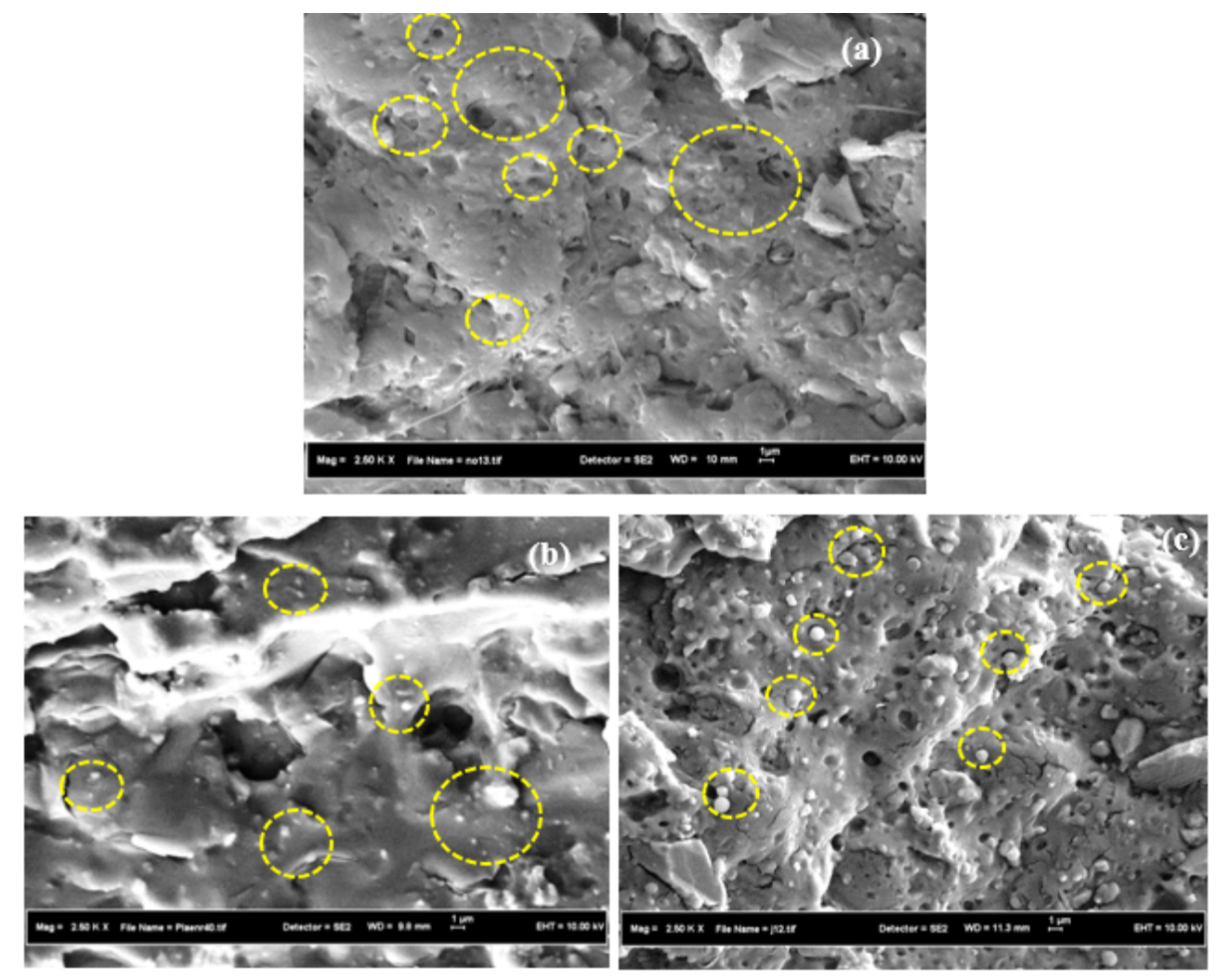

Fig. 3: FESEM images taken from the impact fracture surfaces of (a) PLA/NR, (b) $\mathrm{PLA} / \mathrm{ENR}$, and (c) PLA/CSR, at $1000 \times$ magnification.

\section{Conclusion}

In general, the DMA of all PLA/rubber blends shows a similar decreasing trend of stiffness and $\mathrm{T}_{\mathrm{g}}$ compared to pure PLA. These findings reaffirm earlier observation from the static mechanical analysis and thermal properties analysis. Among all PLA/rubber blends, PLA/CSR exhibits the highest storage modulus and $T_{g}$. All PLA rubber blends also exhibit ductile morphology, with the presence of well-distributed spherical rubber particles and spherical voids throughout the PLA matrix. This observation clearly indicates toughness improvement behaviour for all PLA/rubber blends.

The authors wish to acknowledge the Ministry of Education Malaysia, the financial support from Universiti Teknologi Malaysia (Vot. No. 03H08), Universiti Malaysia Pahang (Vot. No. RDU170321), and the Malaysian Rubber Board for the donation of NR and ENR.

\section{References}

1. R. Liu, S. Luo, J. Cao, Y. Peng, Compos. Part A-Appl. Sci. 51, 33 (2013) 
2. M.S. Huda, L.T. Drzal, A.K. Mohanty, M. Misra, Compos. Sci. Technol. 68, 424 (2008)

3. N. Bitinis, R. Verdejo, P. Cassagnau, M.A. Lopez-Manchado, Mater. Chem. Phys. 129, 823 (2011)

4. E.M. Frick, A.S. Zalusky, M.A. Hillmyer, Biomacromolecules. 4, 216 (2003)

5. S. Ishida, R. Nagasaki, K. Chino, T. Dong, Y. Inoue, J. Appl. Polym. Sci. 113, 558 (2009)

6. R. Jaratrotkamjorn, C. Khaokong, V. Tanrattanakul, J. Appl. Polym. Sci. 124, 5027 (2012)

7. N. Phruksaphithak, C. Noomhorm, Adv. Mater. Res. 486, 406 (2012)

8. P. Sookprasert, N. Hinchiranan, J. Mater. Res. 32, 788 (2017)

9. M. Wang, Y. Wu, Y.D. Li, J.B. Zeng, Polymer Rev. 57, 557 (2017)

10. C. Zhang, C. Man, Y. Pan, W. Wang, L. Jiang, Y. Dan, Polym. Int. 60, 1548 (2011)

11. C. Zhang, W. Wang, Y. Huang, Y. Pan, L. Jiang, Y. Dan, Y. Luo, Z. Peng, Mater. Des. 45, 198 (2013)

12. R. Bagheri, B.T. Marouf, R.A. Pearson, Polym. Rev. 49, 201 (2009)

13. M.S.Z. Mat Desa, A. Hassan, A. Arsad, N.N.B Mohammad, Adv. Mater. Res. 1125, $222(2015)$

14. X. Song, Y. Chen, Y. Xu, C, Wang, BioResources, 9, 1939 (2014)

15. P. Somdee, Natural Rubber Toughened Polylactic Acid. Master of Engineering, Suranaree University of Technology, (2009) 